\title{
Cleistanthin A inhibits the invasion and metastasis of human melanoma cells by inhibiting the expression of matrix metallopeptidase -2 and -9
}

\author{
SHENG PAN $^{1,2^{*}}$, HENGJI CAI ${ }^{*}$, LIXIONG GU $^{1}$ and SHUANGLIN CAO ${ }^{1}$ \\ ${ }^{1}$ Department of Dermatology and Venereology, Affiliated Hospital of Nantong University; \\ ${ }^{2}$ Institute of Nautical Medicine, Nantong University, Nantong, Jiangsu 226001, P.R. China
}

Received December 22, 2015; Accepted July 7, 2017

DOI: $10.3892 / \mathrm{ol} .2017 .6917$

\begin{abstract}
It has been demonstrated that numerous types of metastatic cancer overexpress vacuolar-type $\mathrm{H}^{+}(\mathrm{V})$-ATPases. It may be possible to inhibit the growth and metastasis of human cancer cells by inhibiting V-ATPases. It was previously reported that diphyllin, a novel V-ATPase inhibitor, can inhibit the migration and invasion of SGC7901 human gastric cancer cells; however, the effects of cleistanthin A (CA), a diphyllin glycoside, on melanoma cells has not been demonstrated. The present study aimed to investigate the effect of CA as a V-ATPase inhibitor and its effects on the invasion and metastasis of A375 cells. The results of an MTT assay in the present study indicated that the growth inhibition of A375 cells by CA was induced in a dose- and time-dependent manner; however, A375 cell viability was not significantly affected by low concentrations $(0.03,0.1$ and $0.3 \mu \mathrm{M})$ after $24 \mathrm{~h}$. Similar results were obtained by viable cell counting with trypan blue. Therefore, these concentrations of CA were selected for the treatment of A375 cells in further experiments. It was demonstrated that CA inhibited the expression of V-ATPases in a dose-dependent manner and decreased the internal $\mathrm{pH}$ level of A375 cells. Alterations to the lysosomal pH were associated with the CA concentration. Furthermore, CA treatment induced a significant decrease in cell migration and invasion, as demonstrated with wound-healing and Transwell assays. Gelatin zymography and western blot analysis demonstrated that the expression levels of matrix metallopeptidase (MMP)-2
\end{abstract}

Correspondence to: Dr Lixiong Gu or Professor Shuanglin Cao, Department of Dermatology and Venereology, Affiliated Hospital of Nantong University, 20 Xisi Road, Nantong, Jiangsu 226001, P.R. China

E-mail: pifuxiong@163.com

E-mail: pifucao@163.com

${ }^{*}$ Contributed equally

Key words: vacuolar-adenosine triphosphates, cleistanthin A, melanoma, invasion, metastasis and -9 decreased following CA treatment. Therefore, CA can be characterized as a novel V-ATPase inhibitor for the treatment of melanoma that may inhibit invasion and metastasis by downregulating the expression of MMP-2 and -9.

\section{Introduction}

Cutaneous melanoma is the deadliest form of skin cancer, which arises from melanocytes and their precursors (1). Despite major efforts to identify novel therapeutic tools to treat metastatic melanoma, durable regression remains a rare event in patients with advanced disease, and no significant benefit in survival time has been achieved with targeted inhibitors (2).

A previous study revealed that an acidic tumor microenvironment is critical to cancer progression and metastasis (3). The majority of tumors develop in a pathophysiologic microenvironment that is characterized by low oxygen tension $\left(\mathrm{pO}_{2}\right)$, elevated interstitial fluid pressure, low glucose concentration, high lactate concentration, low extracellular $\mathrm{pH}$ and/or energy deprivation $(4,5)$. This hostile microenvironment activates a number of transcription factors, including hypoxia-inducible factor-1, leading to the upregulated expression of a large number of gene products that promote malignant progression and metastatic dissemination (6,7). In addition, cell surface vacuolar-type $\mathrm{H}^{+}(\mathrm{V})$-ATPase activity has been postulated to create an acidic extracellular microenvironment, which is required for the activation of proteases critical for tumor cell invasion (8).

V-ATPases are ubiquitously expressed ATP-dependent proton pumps that may regulate the $\mathrm{pH}$ in endomembrane systems (9). They are overexpressed in a number of types of metastatic cancer and are positively associated with invasion and metastasis (10). It has been demonstrated that pharmacologic or genetic reductions of V-ATPase activity significantly reduce the migration of invasive tumor cells in vitro (9). For example, the V-ATPase inhibitor archazolid abrogated tumor dissemination in a syngeneic mouse 4T1 breast tumor metastasis model (9). Consistent with this, the inhibition of V-ATPase with concanamycin or short hairpin RNA targeting the V1E subunit reduced matrix metallopeptidase (MMP)-9 activity (11). Bafilomycin and concanamycin were the first discovered V-ATP inhibitors (12); however, as they also inhibit 
mitochondrial ATP enzymes and affect the function of mitochondria in normal cells, they lead to cell death (13) and so are difficult to apply in clinical practice. Recently, cleistanthin A (CA), a natural compound, was demonstrated to inhibit the activity of V-ATPase in HepG2 cells and to neutralize the $\mathrm{pH}$ of lysosomes at nanomolar concentrations (14); to the best of our knowledge, no previous studies have assessed how it may affect tumor cell motility and migration.

The present study aimed to investigate whether CA may inhibit the V-ATPases of A375 cells and to explore the potential underlying mechanisms. It was revealed that CA inhibits the invasion and migration of A375 cells in vitro.

\section{Materials and methods}

Chemicals and materials. RPMI-1640 and fetal bovine serum (FBS) were acquired from Gibco (Thermo Fisher Scientific, Inc., Waltham, MA, USA). Penicillin and streptomycin were obtained from Thermo Fisher Scientific, Inc. Matrigel was purchased from Beijing Unique Biotechnology Co., Ltd. (Beijing, China). A V-ATPase-specific kit was supplied by Shanghai GenePharma Co., Ltd. (Shanghai, China). The $\mathrm{pH}$ sensitive fluorescent probe 20,70-bis-(2-carboxyethyl)-5-carboxyfluorescein (BCECF), was acquired from the Beyotime Institute of Biotechnology (Haimen, China). The pH LysoTracker Red lysosomal fluorescent probe was purchased from Invitrogen (Thermo Fisher Scientific, Inc.) and the nuclear dye Hoechst $33258(5 \mu \mathrm{g} / \mathrm{ml})$ was purchased from the Beyotime Institute of Biotechnology. CA was synthesized by the Institute of Nautical Medicine, Nantong University (Nantong, China). Bafilomycin A1 was obtained from Shanghai GenePharma Co., Ltd. CA and bafilomycin A1 were dissolved in dimethylsulfoxide (DMSO) and stored at $-4^{\circ} \mathrm{C}$ until analysis.

Cell culture. A375 human melanoma cells were kindly provided by the Institute of Dermatology, Chinese Academy of Medical Sciences and Peking Union Medical College (Beijing, China). Cells were cultured in RPMI-1640 supplemented with $10 \%$ FBS and antibiotics $(100 \mathrm{U} / \mathrm{ml}$ penicillin and $100 \mu \mathrm{g} / \mathrm{ml}$ streptomycin) in humidified air with $5 \% \mathrm{CO}_{2}$ at $37^{\circ} \mathrm{C}$ throughout the study.

Proliferation assay. Cell proliferation was determined with an MTT colorimetric assay and trypan blue viable cell counting. Each experiment was repeated $>3$ times. For the MTT colorimetric assay, A375 cells ( $1 \times 10^{4} /$ well) were plated in 96-well plates in $200 \mu \mathrm{l}$ of medium and treated with various concentrations of CA $(0,0.001,0.01,0.03,0.1,0.3$ and $1 \mu \mathrm{M})$ dissolved in $100 \%$ DMSO, with final DMSO concentrations $<0.1 \%$. Control cells were treated with RPMI-1640 supplemented with $0.1 \%$ DMSO. Following 24 or $72 \mathrm{~h}, 100 \mu \mathrm{l} 5 \mathrm{mg} / \mathrm{ml}$ MTT was added and the cells were cultured for another $4 \mathrm{~h}$. This was followed by adding $100 \mu 115 \%$ SDS per well. The absorbance at $570 \mathrm{~nm}$ was evaluated using a microplate reader (SN209941; BioTek Instruments, Inc., Winooski, VT, USA), using wells without cells as blanks and using untreated cells as the negative control. The viable cell counting using trypan blue was performed using A375 cells cultured in 6-well plates in RPMI-1640 supplemented with $10 \%$ FBS for 24 h. Subsequently, various concentrations of CA $(0,0.03,0.1$ and $0.3 \mu \mathrm{M})$, RPMI-1640 supplemented with $0.1 \%$ DMSO and bafilomycin A1 $(0.1 \mu \mathrm{M})$ were added. At $24 \mathrm{~h}$, the cells were trypsinized; suspended cells and trypan blue were mixed 1:1 and the number of viable cells was counted using a haemocytometer.

Wound-healing assay. The in vitro wound-healing assay was used to observe the migration of A375 cells following CA treatment. Cells $\left(1 \times 10^{6}\right.$ cells $\left./ \mathrm{ml}\right)$ were seeded into a 6 -well plate and incubated for $24 \mathrm{~h}$. The center of the cell monolayer was then scraped with a sterile micropipette tip to create a straight gap of constant width. The wells were washed with PBS and the cells were exposed to various concentrations of CA $(0,0.03,0.1$ and $0.3 \mu \mathrm{M})$ or bafilomycin $\mathrm{A} 1(0.1 \mu \mathrm{M})$ (as the positive control). Wound closure was imaged at 0 and $24 \mathrm{~h}$ using an inverted light microscope (magnification, x200) (Leica Microsystems GmbH, Wetzlar, Germany).

Matrigel invasion assay. For assessment of the motility of A375 melanoma cells treated with CA and bafilomycin A1, an invasion assay was performed in a 24-well Transwell plate with $8 \mu \mathrm{m}$ pore filter inserts (Corning Incorporated, Corning, NY, USA) coated with $50 \mu 1$ Matrigel. The cells were then suspended at a density of $1 \times 10^{5}$ cells per chamber in $200 \mu 1 \mathrm{RPMI}-1640$ with CA $(0,0.03,0.1$ and $0.3 \mu \mathrm{M})$ or bafilomycin A1 $(0.1 \mu \mathrm{M})$, added to chamber inserts in wells filled with $0.6 \mathrm{ml}$ of RPMI-1640 supplemented with $20 \%$ FBS as the chemoattractant and incubated for $24 \mathrm{~h}$. The cells and Matrigel on the upper side of inserts were completely removed by swabbing. The transmigrated cells on the lower side of the membrane and well bottom were fixed for $30 \mathrm{~min}$ with formaldehyde and stained for 5 min with $0.1 \%$ of crystal violet at room temperature. The number of cells was observed using an inverted microscope (magnification, x200).

$V$-ATPase activity. V-ATPase activity was evaluated using the V-ATPase-specific kit (Genmed Scientifics, Inc., Arlington, MA, USA), according to the manufacturer's protocol. Briefly, $8 \times 10^{5}$ cells untreated or treated with $\mathrm{CA}$ or bafilomycin A1 $(0.1 \mu \mathrm{M})$ in RPMI-1640 with 10\% FBS were incubated for $24 \mathrm{~h}$. The supernatant was discarded and then cells were washed with reagent A 2-3 times, finally discard cleaning fluid. Each sample had $60 \mu \mathrm{l}$ Genmed lysis liquid (reagent B) added to it and the cells were scraped down into the Eppendorf tube. The tube was incubated on ice for $30-50 \mathrm{~min}$ in the ice to lyse cells and centrifuged at $4^{\circ} \mathrm{C}, 10 \mathrm{~min}$ at $13,201 \mathrm{x} \mathrm{g}$. The supernatant contains the cell lysate and its protein concentration was determined with a bicinchoninic acid (BCA) assay (Thermo Fisher Scientific, Inc.). V-ATPase activity was detected using a microplate reader.

Determination of intracellular $\mathrm{pH}$ values. The internal $\mathrm{pH}$ (pHi) value was evaluated in the cell monolayer using the $\mathrm{pH}$ sensitive fluorescent probe BCECF. A standard curve was established using a RF-5301PC fluorescent spectrophotometer (Shimadzu Corporation, Kyoto, Japan). Cells were treated with CA $(0,0.03,0.1$ and $0.3 \mu \mathrm{M})$ for $24 \mathrm{~h}$ prior to the application of BCECF as previously described (15). The fluorescence intensity at $490 \mathrm{~nm}$ was recorded, and the pHi value was determined according to the $\mathrm{pHi}$ standard curve. 
Immunofluorescence staining analysis. Prior to seeding cells, aseptic glasses were placed on 6-well plates. A total of $1.2 \times 10^{4}$ cells in the logarithmic growth phase were seeded on 6-well plates with pre-paved glasses and treated with $\mathrm{CA}$ $(0,0.03,0.1$ and $0.3 \mu \mathrm{M})$ or bafilomycin A1 $(0.1 \mu \mathrm{M})$ for $24 \mathrm{~h}$. Then incubated $100 \mathrm{nM}$ lysosomal fluorescent probe (Invitrogen; Thermo Fisher Scientific, Inc.), LysoTracker, with CA and bafilomycin A1 $(0.1 \mu \mathrm{M})$ for $3 \mathrm{~h}$. Cells were then washed with PBS, fixed with $4 \%$ formaldehyde for $15 \mathrm{~min}$ at room temperature and washed again with PBS for 2-3 times, then they were stained with DAPI $(10 \mu \mathrm{g} / \mathrm{ml})$ for $5 \mathrm{~min}$ at room temperature. Then discarded the dye solution, washed again with PBS for 2-3 times, and pasted the glasses with quenching inhibitor, Finally, a DMRXA2 Leica laser confocal microscope (magnification, x63; oil mirror) was used to observe the cells.

Gelatin zymography. The protein content of supernatants from cells treated with $0,0.03,0.1$ and $0.3 \mu \mathrm{M}$ CA or bafilomycin A1 $(0.1 \mu \mathrm{M})$ for $24 \mathrm{~h}$ was determined using a BCA assay following centrifugation at $13,201 \times \mathrm{g}$ at $4^{\circ} \mathrm{C}$. Equal amounts of protein $(25 \mu \mathrm{g})$ for each sample were mixed with $5 \mathrm{X}$ loading buffer $[50 \mathrm{mmol} / 1$ Tris- $\mathrm{HCl}(\mathrm{pH} 6.8), 10 \%$ glycerol, $2 \%$ SDS and $0.1 \%$ bromophenol blue] and loaded onto a $10 \%$ SDS-PAGE containing $0.1 \%$ gelatin. Following electrophoresis, gels were rinsed twice in $0.25 \%$ Triton X-100 for $40 \mathrm{~min}$ at room temperature and then incubated at $37^{\circ} \mathrm{C}$ in developing buffer (50 mmol/1 Tris, $\mathrm{pH}$ 7.5-7.6, $10 \mathrm{mmol} / \mathrm{l}$ $\mathrm{CaCl}_{2}, 0.02 \% \mathrm{NaN}_{3}$ and $150 \mathrm{mmol} / 1 \mathrm{NaCl}$ ) for $42 \mathrm{~h}$. The gels were then stained with $0.05 \%$ Coomassie Brilliant Blue R-250 in 30\% methanol and $10 \%$ glacial acetic acid for $3 \mathrm{~h}$, and subsequently destained in $30 \%$ methanol and $10 \%$ glacial acetic acid for $30 \mathrm{~min}, 20 \%$ methanol and $10 \%$ glacial acetic acid for $1 \mathrm{~h}$ and $10 \%$ methanol and 5\% glacial acetic acid for $2 \mathrm{~h}$. Each staining step was performed at room temperature. Images were obtained using the Gel Image Formation system (LI-COR Biosciences, Lincoln, NE, USA) and analyzed using ImageJ software (National Institutes of Health, Bethesda, MD, USA). Pro-MMP-9 and activated gelatinase exhibit gelatinolytic activity in gelatin zymography (16). Thus, the samples were separated by SDS-PAGE (0.1\% gelatin). However, during electrophoresis, SDS binds with MMPs of samples (the binding is reversible), so that MMPs cannot perform their role in the decomposition of gelatin. The activities of MMP-2 and MMP-9 were recovered in the buffer system with two valence metal ions and the gelatin in the gel was hydrolyzed at each migration position. Finally, the gels were stained and decolorized, which appears as white bands on the blue background. The strength of band was proportional to the activity of MMP-2 and MMP-9.

Western blot analysis. Cells were seeded into $6 \mathrm{~cm}$ dishes and reached $60-80 \%$ confluence after $24 \mathrm{~h}$. CA at various concentrations $(0,0.03,0.1$ and $0.3 \mu \mathrm{M})$ and bafilomycin A1 $(0.1 \mu \mathrm{M})$ were added. At $24 \mathrm{~h}$, total cell lysates were collected using lysis buffer (Beyotime Institute of Biotechnology) containing $0.01 \%$ protease inhibitor cocktail (Thermo Fisher Scientific, Inc.) and sonication with an ultrasonic processor. The cell lysates were microcentrifuged at $13,201 \mathrm{x}$ g for $10 \mathrm{~min}$ at $4^{\circ} \mathrm{C}$ and the supernatant was collected. The protein concentrations of total cell lysates were determined with a BCA assay. The proteins were separated by $10 \%$ SDS-PAGE and electrophoretically transferred onto polyvinylidenefluoride membranes. The membranes were blocked in 5\% skim milk for $1 \mathrm{~h}$ at room temperature. Subsequently the membranes were probed using primary antibodies against MMP-2 (cat. no. 6E3F8), MMP-9 (cat. no. ab38898) (1:500; Abcam, Cambridge, UK) and $\beta$-actin (cat. no. A1978; 1:5,000; Sigma-Aldrich; Merck $\mathrm{KGaA}$, Darmstadt, Germany) overnight at $4^{\circ} \mathrm{C}$ and then incubated with the secondary antibody [goat anti-mouse IRDye 800CW IgG (H+L); cat. no. P/N 925-32210; 1:10,000; LI-COR Biosciences, Lincoln, NE, USA, and goat anti-rabbit IR Dye 800CW IgG (H+L); cat. no. P/N 925-32211 (just for anti-MMP-9 antibody); 1:10,000; LI-COR Biosciences] for $1.5 \mathrm{~h}$ at room temperature avoiding light. Finally, the protein expression was detected using an ECL detection kit (Beyotime Institute of Biotechnology).

Data analysis. All experiments were conducted at least 3 times in duplicates/triplicates. Results are presented as the mean \pm standard deviation. One-way analysis of variance with a post hoc Tukey's test was performed using GraphPad Prism 5 software (GraphPad Software, Inc., La Jolla, CA, USA). P<0.05 was considered to indicate a statistically significant difference.

\section{Results}

CA treatment inhibits the proliferation of A375 cells. The effect of treatment with CA on cell viability was determined with an MTT assay. Cells were in various concentrations $(0$, $0.001,0.01,0.03,0.1,0.3$ or $1 \mu \mathrm{M})$ of CA. Growth inhibition was induced in a dose- and time-dependent manner (Fig. 1A and B). As presented in Fig. 1A, cell viability was not significantly affected by low concentrations at $24 \mathrm{~h}$ compared with high-concentration treatment. Similar results were obtained from viable cell counting with trypan blue staining with CA concentrations of $0.03,0.1$ and $0.3 \mu \mathrm{M}$ (Fig. 1C). Therefore, a concentration range of $0.03,0.1$ and $0.3 \mu \mathrm{M}$ CA was selected for the subsequent experiments.

$C A$ inhibits the activity of $V$-ATPases, increases the acidity of the cytoplasm and increases the alkalinity of the lysosome in A375 cells. To determine whether CA inhibits the expression of V-ATPase, A375 cells were treated with DMSO, CA (0.03, 0.1 and $0.3 \mu \mathrm{M}$ ) or bafilomycin A1 for $24 \mathrm{~h}$ and were analyzed for V-ATPase activity using a V-ATPase-specific kit.

Following a 24-h CA treatment at various concentrations, the expression level of V-ATPase was altered when compared with the control group (Fig. 2A). The expression levels of $\mathrm{V}$-ATPase in the low concentration group were significantly less compared with in the control group $(\mathrm{P}<0.001)$. A dose-dependent association was observed between the CA concentration and the expression level of V-ATPase.

Following the inhibition of V-ATPase, hydrogen ions in the cytoplasm can no longer be transported from the cell. Therefore, the present study investigated the pHi of A375 cells treated with $\mathrm{CA}$. The standard curve of fluorescence intensity vs. the pHi value of A375 cells is presented in Fig. 2B. According to regression analysis, the mathematic 

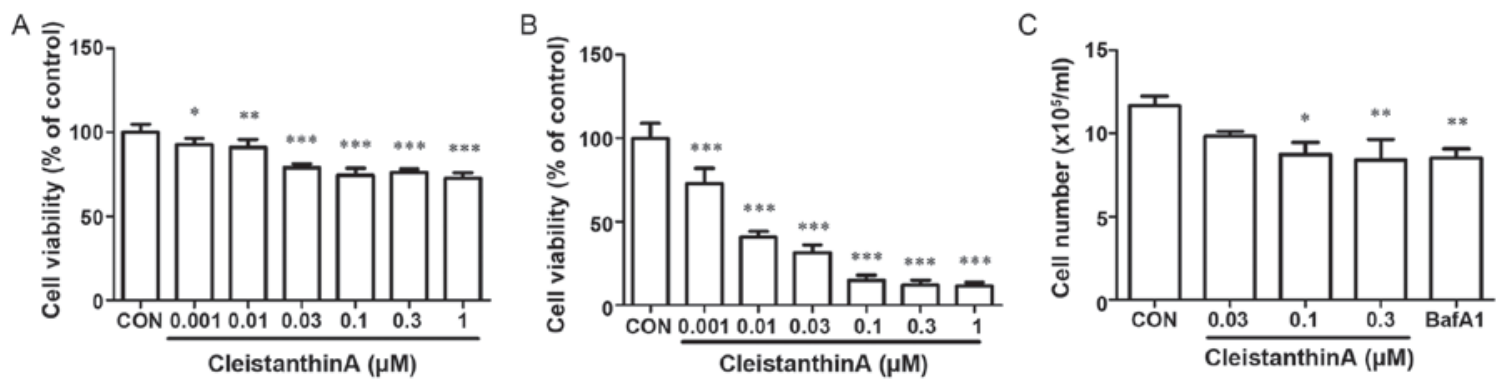

Figure 1. The effect of CA treatment on cell proliferation. (A) A375 cells were treated with CA for $24 \mathrm{~h}$ and cell proliferation was analyzed with an MTT assay $(\mathrm{n}=6)$. (B) A375 cells were treated with CA for $72 \mathrm{~h}$ and cell proliferation was analyzed by an MTT assay (n=6). (C) The number of viable A375 cells was determined with with trypan blue staining. The cells were treated with various concentrations of $\mathrm{CA}(0,0.03,0.1$ and $0.3 \mu \mathrm{M})$, or bafilomycin A1 as a positive control, for $24 \mathrm{~h}(\mathrm{n}=3)$. Data are presented as the mean \pm standard deviation. ${ }^{*} \mathrm{P}<0.05,{ }^{* *} \mathrm{P}<0.01$ and ${ }^{* * * *} \mathrm{P}<0.001$ vs. control. CA, cleistanthin A; CON, control.
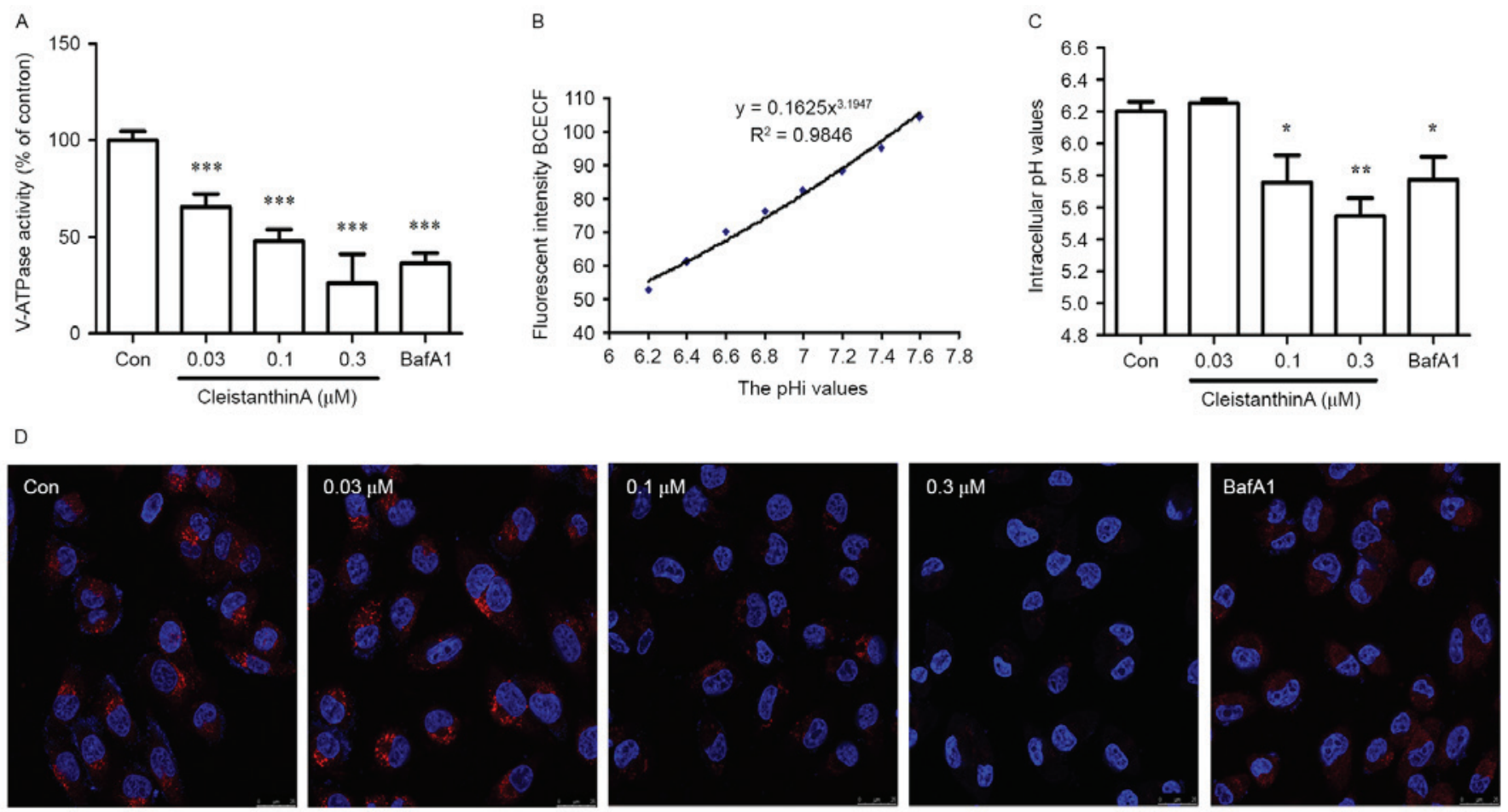

Figure 2. The effect of CA treatment on the V-ATPase activity level and pHi values of A375 cells. (A) A375 cells were treated with CA ( $0,0.03,0.1$ and $0.3 \mu \mathrm{M})$ or bafilomycin A1 for $24 \mathrm{~h}$. The V-ATPase activity level was determined using a V-ATPase-specific kit $(\mathrm{n}=3)$. (B) Standard curve of fluorescence intensity of BCECF vs. the pHi value of A375 cells. (C) The pHi values of A375 cells following CA or bafilomycin A1 treatment for $24 \mathrm{~h}$ ( $\mathrm{n}=3$ ). (D) Lysosomal $\mathrm{pH}$. The lysosomal $\mathrm{pH}$ was analyzed using lysosomal fluorescent probe and DAPI staining subsequent to CA or bafilomycin A1 treatment for $24 \mathrm{~h}$ (magnification, $\mathrm{x} 200) .{ }^{*} \mathrm{P}<0.05,{ }^{* *} \mathrm{P}<0.01$ and ${ }^{* * * *} \mathrm{P}<0.001$ vs. control. CA, cleistanthin A; V-ATPase, vacuolar-type $\mathrm{H}^{+}-\mathrm{ATPase}$; $\mathrm{pHi}$, intracellular pH; BCECF, 20,70-bis-(2-carboxyethyl)-5-carboxyfluorescein; Con, control.

model was established with the equation: $Y=0.1625 X 3.1947$. The pHi values of A375 cells prior to and following CA treatment with various concentrations for $24 \mathrm{~h}$ were calculated based on this formula. As included in Fig. 2C, it was revealed that the pHi values in A375 cells treated with $\mathrm{CA}$ at concentrations of 0.1 and $0.3 \mu \mathrm{M}$ for $24 \mathrm{~h}$ were significantly lower compared with that in the control group $(\mathrm{P}<0.05$ and $\mathrm{P}<0.01$ respectively).

It was determined whether CA can alkalize the lysosomal $\mathrm{pH}$ using the LysoTracker Red lysosomal fluorescent probe. The lysosome is usually acidic, which induces the production of red fluorescence; when the lysosomal $\mathrm{pH}$ increases, the intensity of red fluorescence decreases. The present study determined the lysosomal $\mathrm{pH}$ of A375 cells following treatment with $\mathrm{CA}$ and bafilomycin A1. It was revealed that the red fluorescence intensity was decreased in a dose-dependent manner (Fig. 2D).

CA inhibits cell migration. The wound-healing assay was used to investigate the migration of A375 cells cultured with the investigated concentrations $(0,0.03,0.1$, and $0.3 \mu \mathrm{M})$ of $\mathrm{CA}$ and the positive control drug (bafilomycin A1). The results revealed that CA significantly reduced the migration of A375 cells in a dose-dependent manner at $24 \mathrm{~h}$ (Fig. 3A and B).

CA inhibits cell invasion. A significant difference was observed in the motility of A375 cells treated with CA in the Transwell assay. Following a 24-h treatment with CA, the invasion ability 
A

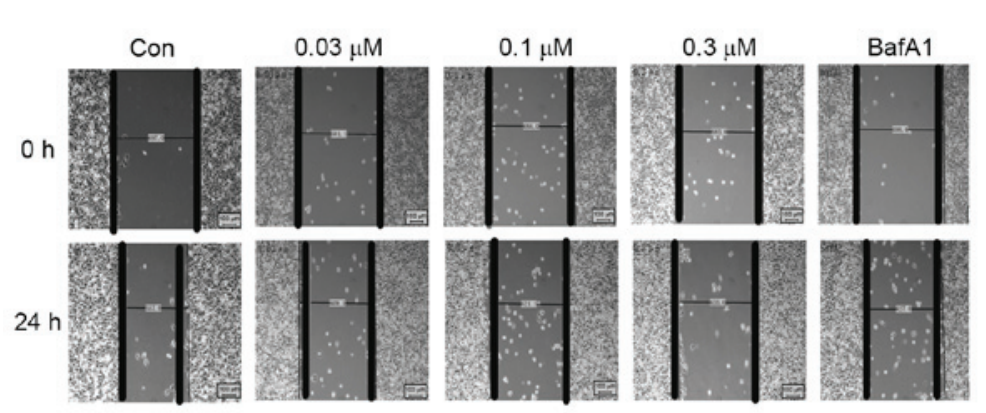

C

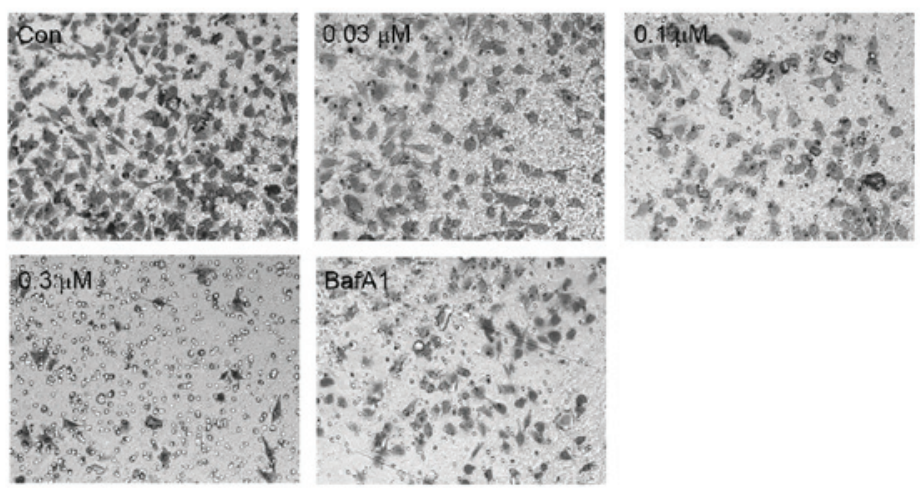

$B$

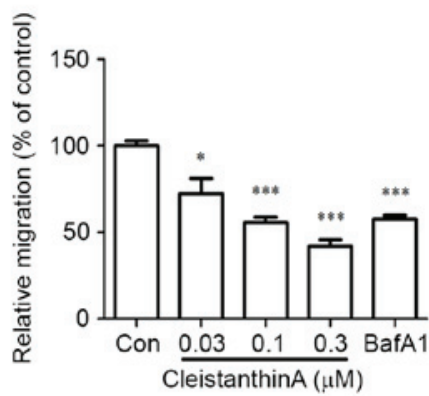

D



Figure 3. Effect of CA on the cell migration and invasion of A375 cells. (A) A375 cells were wounded and then treated with CA $(0,0.03,0.1$ and $0.3 \mu \mathrm{M})$ or bafilomycin A1 for $24 \mathrm{~h}$. At 0 and 24 h, phase-contrast images of the wounds were captured (magnification, x200). (B) Histogram of cell mobility. Data are presented as the percentage change (means $\pm \mathrm{SD}$ ) and represent three independent experiments. (C) Cell invasion at $24 \mathrm{~h}$ following treatment with CA was evaluated by a Matrigel invasion assay. Representative microscopic images following CA treatment are included (magnification, x200). (D) Comparison of the rate of A375 cell invasion. Data are expressed as the percentage change (means \pm SD) and represent three independent experiments. ${ }^{*} \mathrm{P}<0.05$ and ${ }^{* * * *} \mathrm{P}<0.001$ vs. the control. CA, cleistanthin A; SD, standard deviation; Con, control.

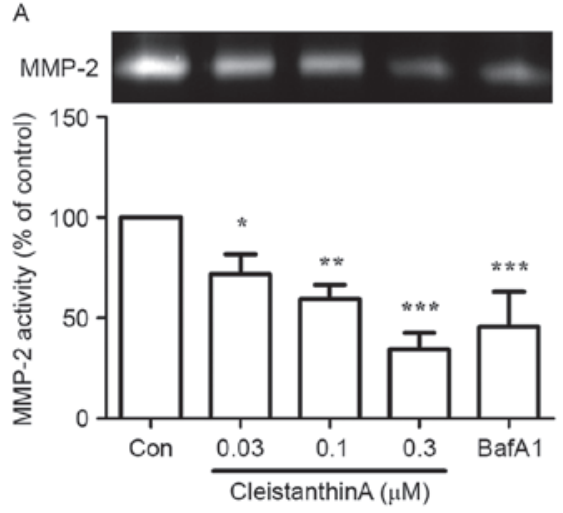

C
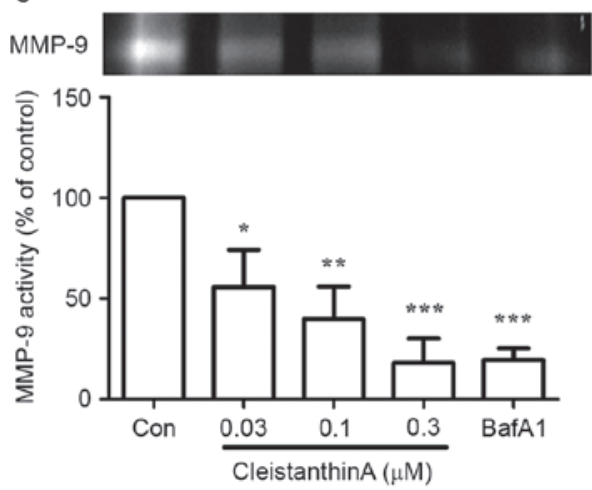


Figure 4. Effects of CA on the activity and expression of MMP-2 and MMP-9 in A375 cells. A375 cells were treated with CA or bafilomycin A1. The (A) activity and (B) expression of MMP-2, and the (C) activity and (D) expression of MMP-9 were determined with gelatin zymography and western blot analysis. Data represents 3 replicates and 3 repeats. Data are presented as the mean \pm standard deviation. ${ }^{*} \mathrm{P}<0.05,{ }^{* *} \mathrm{P}<0.01$ and ${ }^{* * * *} \mathrm{P}<0.001$. CA, cleistanthin $\mathrm{A}$; MMP, matrix metallopeptidase; Con, control. 
of A375 cells was significantly reduced $(\mathrm{P}<0.001$ vs. no treatment) in the Matrigel invasion assay (Fig. 3C and D).

Effect of CA treatment on the expression and secretion of $M M P-2$ and MMP-9. It has been reported that V-ATPase inhibition reduces the activity of MMP-9 (11). Therefore, the present study investigated whether CA can affect the activity and expression levels of MMP-9 and -2 with gelatin zymography and western blot analysis, respectively.

Gelatin zymography was used to analyze the activity of secreted MMP-2 and -9 in A375 cells treated with or without CA. Fig. 4A demonstrated that the activity of MMP-2 in the $0.03,0.1$ and $0.3 \mu \mathrm{M} \mathrm{CA}$ groups was significantly lower compared with the control group in a dose-dependent manner $(\mathrm{P}<0.05, \mathrm{P}<0.01, \mathrm{P}<0.001$, respectively). The protein expression level of MMP-2 was also reduced with CA treatment (Fig. 4B). A similar result was obtained for MMP-9 (Fig. 4C and D).

\section{Discussion}

$\mathrm{CA}$, a natural compound, may exhibit anti-proliferative activity in vitro against MCF-7, HeLa, HepG2, HCT-116 and U251 cancer cell lines (14). In the present study the toxic effect of CA on A375 cells was preliminary investigated. It was revealed that the growth inhibition of A375 cells was induced in a dose- and time-dependent manner (Fig. 1A and B); however, the viability of A375 human melanoma cells was not significantly affected at low concentrations at $24 \mathrm{~h}$, compared with high-concentration treatment. CA also inhibited cell invasion and metastasis in a dose-dependent manner at $24 \mathrm{~h}$. Based on these results, CA may have potential as an anticancer agent.

It was previously reported that blocking the V-ATPases can inhibit the growth and metastasis of human cancer cells $(10,17)$. It has also been demonstrated that diphyllin inhibits V-ATPase, and therefore, lysosomal acidification in osteoclasts, which leads to the abrogation of bone resorption (18). The present study suggested that CA inhibits the expression of V-ATPases on A375 cells at concentrations of $0.03,0.1$ or $0.3 \mu \mathrm{M}$. The administration of CA may inhibit the concentration of V-ATPases in the cell membrane, affecting their role in transporting $\mathrm{H}^{+}$out of the cell, as V-ATPase is a ubiquitous proton-translocating pump of eukaryotic cells (19). The pumps are located in the membranes of vacuoles, lysosomes and other components of the endomembrane system, as well as in certain specialized plasma membranes (19). Therefore, it was inferred that CA may also affect the $\mathrm{pH}$ of lysosomes. The present study evaluated lysosomal $\mathrm{pH}$ with immunofluorescence staining. It was revealed that $\mathrm{CA}$ at concentrations of 0.1 and $0.3 \mu \mathrm{M}$ alkalized the lysosomal $\mathrm{pH}$.

Tumor invasion and metastasis are multistage and multi-factorial processes, regulated by complex mechanisms, including multiple signaling pathways (20). Numerous proteins are associated with regulating cancer cell adhesion, migration and invasion (21). MMPs are a family of zinc-binding proteases that contribute to cancer cell invasion by degrading the extracellular matrix $(22,23)$. MT1-MMP (also known as MMP-14), an activator of proMMP-2, was the first MMP to be identified and the most common member of the MTMMP subfamily involved in pericellular proteolysis associated with cell migration $(24,25)$. The degradation of the basement membrane, e.g., by MMP-2, may be a necessary step in cancer invasion $(26,27)$. The present study demonstrated that the activity and expression levels of MMP-2 and -9 may be inhibited by CA with gelatin zymography and western blot analysis.

In conclusion, the present study revealed that CA is a novel inhibitor of V-ATPases that induced a decrease in A375 cell migration and invasion via the inhibition of the expression of MMP-2 and -9. Recently, it was reported that the transcription of MT1-MMP was regulated by the Wnt signaling pathway $(28,29)$. It is necessary to determine whether CA inhibits the activation of MMPs via the Wnt signaling pathway through further study.

\section{References}

1. Liu J, Fukunaga-Kalabis M, Li L and Herlyn M: Developmental pathways activated in melanocytes and melanoma. Arch Biochem Biophys 563: 13-21, 2014.

2. De Milito A, Canese R, Marino ML, Borghi M, Iero M, Villa A, Venturi G, Lozupone F, Iessi E, Logozzi M, et al: pH-dependent antitumor activity of proton pump inhibitors against human melanoma is mediated by inhibition of tumor acidity. Int $\mathrm{J}$ Cancer 127: 207-219, 2010.

3. Chiche J, Brahimi-Horn MC and Pouysségur J: Tumour hypoxia induces a metabolic shift causing acidosis: A common feature in cancer. J Cell Mol Med 14: 771-794, 2010.

4. Vaupel P, Kallinowski F and Okunieff P: Blood flow, oxygen and nutrient supply, and metabolic microenvironment of human tumors: A review. Cancer Res 49: 6449-6465, 1989.

5. Harguindey S, Orive G, Luis Pedraz J, Paradiso A and Reshkin SJ: The role of $\mathrm{pH}$ dynamics and the $\mathrm{Na}^{+} / \mathrm{H}^{+}$antiporter in the etiopathogenesis and treatment of cancer. Two faces of the same coin-one single nature. Biochim Biophys Acta 1756: 1-24, 2005.

6. Rofstad EK: Microenvironment-induced cancer metastasis. Int J Radiat Biol 76: 589-605, 2000

7. Harris AL: Hypoxia-a key regulatory factor in tumour growth. Nat Rev Cancer 2: 38-47, 2002.

8. Mason SD and Joyce JA: Proteolytic networks in cancer. Trends Cell Biol 21: 228-237, 2011.

9. Wiedmann RM, von Schwarzenberg K, Palamidessi A, Schreiner L, Kubisch R, Liebl J, Schempp C, Trauner D, Vereb G, Zahler S, et al: The V-ATPase-inhibitor archazolid abrogates tumor metastasis via inhibition of endocytic activation of the Rho-GTPase Rac1. Cancer Res 72: 5976-5987, 2012.

10. Fais S, De Milito A, You $\mathrm{H}$ and Qin W: Targeting vacuolar $\mathrm{H}^{+}$-ATPases as a new strategy against cancer. Cancer Res 67: 10627-10630, 2007.

11. Chung C, Mader CC, Schmitz JC, Atladottir J, Fitchev P, Cornwell ML, Koleske AJ, Crawford SE and Gorelick F: The vacuolar-ATPase modulates matrix metalloproteinase isoforms in human pancreatic cancer. Lab Invest 91: 732-743, 2011.

12. Fortini ME and Bilder D: Endocytic regulation of Notch signaling. Curr Opin Genet Dev 19: 323-328, 2009.

13. Vaccari T, Duchi S, Cortese K, Tacchetti C and Bilder D: The vacuolar ATPase is required for physiological as well as pathological activation of the Notch receptor. Development 137: 1825-1832, 2010.

14. Zhang Z, Ma J, Zhu L and Zhao Y: Synthesis and identification of cytotoxic diphyllin glycosides as vacuolar H(+)-ATPase inhibitors. Eur J Med Chem 82: 466-471, 2014.

15. Shen W, Zou X, Chen M, Liu P, Shen Y, Huang S, Guo H and Zhang L: Effects of diphyllin as a novel V-ATPase inhibitor on gastric adenocarcinoma. Eur J Pharmacol 667: 330-338, 2011.

16. Vandooren J, Geurts N, Martens E, Van den Steen PE and Opdenakker G: Zymography methods for visualizing hydrolytic enzymes. Nat Methods 10: 211-220, 2013.

17. Lu X, Qin W, Li J, Tan N, Pan D, Zhang H, Xie L, Yao G, Shu H, Yao M, et al: The growth and metastasis of human hepatocellular carcinoma xenografts are inhibited by small interfering RNA targeting to the subunit ATP6L of proton pump. Cancer Res 65: 6843-6849, 2005.

18. Sørensen MG, Henriksen K, Neutzsky-Wulff AV, Dziegiel MH and Karsdal MA: Diphyllin, a novel and naturally potent V-ATPase inhibitor, abrogates acidification of the osteoclastic resorption lacunae and bone resorption. J Bone Miner Res 22: 1640-1648, 2007. 
19. Yu W, Wang L, Wang Y, Xu X, Zou P, Gong M, Zheng J, You J, Wang H, Mei F and Pei F: A novel tumor metastasis suppressor gene LASS2/TMSG1 interacts with vacuolar ATPase through its homeodomain. J Cell Biochem 114: 570-583, 2013.

20. Takahashi M, Tsunoda T, Seiki M, Nakamura Y and Furukawa Y: Identification of membrane-type matrix metalloproteinase-1 as a target of the beta-catenin/Tcf4 complex in human colorectal cancers. Oncogene 21: 5861-5867, 2002.

21. Ma Y, Zou F, Xiong J, Wan W, Yin L, Li X, Bei Z, Yuan L, Meng S, Wang J and Song G: Effect of Matrine on HPAC cell migration by down-regulating the expression of MT1-MMP via Wnt signaling. Cancer Cell Int 15: 59, 2015.

22. Kessenbrock K, Plaks V and Werb Z: Matrix metalloproteinases: Regulators of the tumor microenvironment. Cell 141: 52-67, 2010.

23. Itoh Y and Seiki M: MT1-MMP: A potent modifier of pericellular microenvironment. J Cell Physiol 206: 1-8, 2006.

24. Kajita M, Itoh Y, Chiba T, Mori H, Okada A, Kinoh H and Seiki M: Membrane-type 1 matrix metalloproteinase cleaves CD44 and promotes cell migration. J Cell Biol 153: 893-904, 2001.
25. Deryugina EI, Ratnikov BI, Postnova TI, Rozanov DV and Strongin AY: Processing of integrin alpha(v) subunit by membrane type 1 matrix metalloproteinase stimulates migration of breast carcinoma cells on vitronectin and enhances tyrosine phosphorylation of focal adhesion kinase. J Biol Chem 277: 9749-9756, 2002.

26. Sato H, Takino T and Miyamori H: Roles of membrane-type matrix metalloproteinase-1 in tumor invasion and metastasis. Cancer Sci 96: 212-217, 2005.

27. Seiki M: Membrane-type 1 matrix metalloproteinase: A key enzyme for tumor invasion. Cancer Lett 194: 1-11, 2003.

28. Knopfová L, Beneš P, Pekarčíková L, Hermanová M, Masařík M, Pernicová Z, Souček K and Smarda J: c-Myb regulates matrix metalloproteinases $1 / 9$, and cathepsin D: Implications for matrix-dependent breast cancer cell invasion and metastasis. Mol Cancer 11: 15, 2012.

29. Yousef EM, Tahir MR, St-Pierre Y and Gaboury LA: MMP-9 expression varies according to molecular subtypes of breast cancer. BMC Cancer 14: 609, 2014. 